\title{
A STUDY OF JOB SATISFACTION AND WORK ENVIRONMENT PERCEPTION AMONG DOCTORS IN A TERTIARY HOSPITAL IN DELHI
}

SUMINDER KAUR, RAHUL SHARMA, RICHA TALWAR, ANITA VERMA, SAUDAN SINGH

\section{ABSTRACT}

BACKGROUND: Many doctors are dissatisfied with their jobs, which is due to long working hours and overwork. This can affect patient care and reduce quality of care. OBJ ECTIVES: To study job satisfaction among doctors in a tertiary hospital in Delhi and the various factors related with it. MATERIALS AND METHODS Data collection was done among $\mathbf{2 5 0}$ doctors on tenure-based job, selected by stratified random sampling, in a teaching hospital in Delhi, by using a self-administered questionnaire. STATISTICAL ANALYSIS: Proportions and Chi-square tests. RESULTS: The mean number of work-hours among doctors was $9.7 \pm 2.7$ hours per day, and the mean number of night shifts was 5.6 per month. About half (49.6\%) of the doctors were dissatisfied with the average number of work-hours per day. Dissatisfaction was significantly more in those who had an average of $>8$ work-hours per day and who had $\geq 8$ night shifts per month. About half (45.6\%) of the doctors considered their salary as 'bad,' and this was significantly more among unmarried doctors, interns and those who had $\geq 8$ night shifts per month. More than half (55.2\%) of the doctors were dissatisfied with their choice of profession, i.e., being a doctor, as compared to other professions. CONCLUSIONS: A significant proportion of doctors were found to be dissatisfied with the average number of their work-hours and salary. Factors like the average number of work-hours per day and the number of night shifts per month were found to have a significant relation with dissatisfaction. Further studies are needed to explore how best the work-hours of doctors could be adjusted to improve their job satisfaction.

Key words: Delhi, doctors, satisfaction, work environment, work-hours DOI: 10.4103/0019-5359.50762

\section{INTRODUCTION}

The prevalence of dissatisfaction among doctors has been given considerable

Department of Community Medicine, Vardhman Mahavir Medical College and Safdarjung Hospital, New Delhi, India

Correspondence:

Dr. Suminder Kaur,

56, Gujral Nagar, Jalandhar -144 001, Punjab, India

E-mail: dr_suminderkaur@yahoo.com importance in recent years as it affects patient satisfaction ${ }^{[1]}$ and can adversely influence patient behavior (e.g., adherence to medical treatment), ${ }^{[2]}$ leading to a reduction in the quality of care. At the individual level, low level of job satisfaction and high level of job stress are threats to mental and physical health, quality of life, goal achievement and personal development. At the workplace, these conditions can lead to increased absenteeism, conflict and turnover; and reduced quality 
and quantity of work. ${ }^{[3]}$ Job satisfaction is also important to the future recruitment of new doctors and retention of the existing doctors, in addition to the productivity and quality of the services provided by the doctors, who are an essential and integral component of our medical care system. ${ }^{[4]}$

Although many studies have been conducted to find out the level of job satisfaction among doctors, yet very few have been conducted in India, especially in the recent past. This study was planned with the objective of determining the level of job satisfaction among doctors working in a tertiary hospital in Delhi and the various factors associated with it.

\section{MATERIALS AND METHODS}

Delhi is the capital of India, with a population of 13.8 million. There are 6 teaching hospitals located in Delhi itself, and the present study was carried out in one of these. There are 2 types of doctors in a hospital - those on permanent faculty posts; and those on tenurebased jobs: senior residents, junior residents, postgraduate students and interns. Senior residency is the period of in-house training for duration of 3 years after the completion of postgraduation, while junior residency is the period of in-house training for duration of 1 year after the completion of graduation. Postgraduation is a term of 3 years after MBBS. Internship is the 1-year rotatory posting at the end of the MBBS course. These doctors were included in the present study because it has been found in some studies ${ }^{[1,5]}$ that resident doctors have greater dissatisfaction and stress due to their long working hours, less independence in work and more stressful promotional conditions than the faculty. This cross-sectional study was conducted in one of the tertiary care hospitals in Delhi in September 2008.

Stratified random sampling was done with the target being to cover at least $25 \%$ in each group of doctors. Ethical clearance was obtained. Informed consent was taken from all the participants. A self-administered close-ended questionnaire was used to obtain information from the doctors on various aspects of job satisfaction. These included satisfaction with the average number of working hours per day, perception of work environment, perception of the relations with colleagues and satisfaction with salary. Satisfaction with their choice of profession, i.e., being a doctor, as compared to other professions was also asked about. The data collection was anonymous, and the questionnaires were collected in closed boxes which were opened only at the time of analysis. The data thus collected was converted into a computer-based spreadsheet. The statistical analysis included calculating proportions and applying Chi-square tests for test of significance.

\section{RESULTS}

A total of 250 doctors were included in the study. The mean age of the doctors was 27.9 \pm 3.2 years, with $176(70.4 \%)$ in the age group of 25-30 years. About two thirds (166; 66.4\%) of the doctors were male and one third (84; $33.6 \%)$ were female. Majority (175; 70\%) were unmarried, $72(28.8 \%)$ were married while 3 $(1.2 \%)$ were divorced. Out of the 250 doctors, $67(26.8 \%)$ resided in their own house; 87 $(35.2 \%)$, in a hostel; and $96(38 \%)$, in rented 
accommodation. The mean number of working hours in the last month prior to the interview was $9.7 \pm 2.7$ hours per day, with a range of 3-20 hours. The mean number of night shifts was 5.6 per month, with a range of 0-17 night shifts / month.

\section{Satisfaction with the average number of working hours per day}

It was found that about half (124; 49.6\%) of the doctors were dissatisfied with the average number of working hours per day. Dissatisfaction was significantly greater among doctors who had an average of $>8$ work-hours per day (Chi-square $=15.05, P<0.001$ ), those who had $\geq 8$ night shifts per month (i.e., twice a week) (Chi-square $=18.40, P<0.001$ ), and those who had more than 1 adverse event in the family in the last 1 year (Chi square $=8.61$, $P=0.013)$. However, it was not significantly associated with gender (Chi square $=0.96$, $P=0.33$ ), marital status (Chi-square $=2.18$, $P=0.14$ ) or designation (Chi-square $=0.63$, $P=0.89$ ).

\section{Perception of work environment}

Work environment was perceived as 'good' by 89 (35.6\%) doctors; 'average,' by 131 (52.4\%) doctors; and 'bad,' by 30 (12\%) doctors. Table 1 shows that the doctors who had an average of $>8$ work-hours per day (Chi-square $=9.08$, $P=0.01)$ and those who had $\geq 8 \mathrm{night}$ shifts per month (Chi-square $=16.60, P=$ 0.002 ) were more likely to perceive the work environment as bad.

\section{Perception of relations with colleagues at workplace}

About two thirds $(166 ; 66.4 \%)$ of the doctors perceived their relations with the colleagues as being good, while one third (84; $33.6 \%)$ considered their relations as being average / bad. The doctors who had $\geq 8$ night shifts per month (i.e., twice a week) (Chi-square $=6.96, P=0.03$ ) and those who had more than 1 adverse event in the family in the last 1 year (Chi-square $=16.42, P=0.003$ ) were more likely to perceive their relations with the colleagues at workplace as being bad.

Table 1: Variables associated with the perception of work environment among 250 doctors working in a tertiary hospital

\begin{tabular}{|c|c|c|c|c|c|}
\hline Variable & $\begin{array}{l}\text { Good } \\
n(\%)\end{array}$ & $\begin{array}{c}\text { Average } \\
n(\%)\end{array}$ & $\begin{array}{c}\mathrm{Bad} \\
n(\%)\end{array}$ & $\begin{array}{c}\text { Total } \\
n\end{array}$ & $p^{*}$ \\
\hline \multicolumn{6}{|l|}{ Gender } \\
\hline Male & $62(37.3)$ & $83(50.0)$ & $21(12.7)$ & 166 & \multirow[t]{2}{*}{0.57} \\
\hline Female & $27(32.1)$ & $48(57.1)$ & $9(10.7)$ & 84 & \\
\hline \multicolumn{6}{|l|}{ Marital status } \\
\hline Single & $56(32.0)$ & $98(56.0)$ & $21(12.0)$ & 175 & \multirow[t]{2}{*}{0.12} \\
\hline Married & $33(45.8)$ & $33(45.8)$ & $6(8.3)$ & 72 & \\
\hline \multicolumn{6}{|c|}{ Work-hours/day } \\
\hline$\leq 8$ hours & $42(47.7)$ & $36(40.9)$ & $10(11.4)$ & 88 & \multirow[t]{2}{*}{0.01} \\
\hline$>8$ hours & $47(29.0)$ & $95(58.6)$ & $20(12.3)$ & 162 & \\
\hline \multicolumn{6}{|c|}{ Night-shifts/month } \\
\hline 0 & $32(58.2)$ & $19(34.5)$ & $4(7.3)$ & 55 & \multirow{3}{*}{0.002} \\
\hline$<8$ & $35(29.2)$ & $71(59.2)$ & $14(11.7)$ & 120 & \\
\hline$\geq 8$ & $22(29.3)$ & $41(54.7)$ & $12(16.0)$ & 75 & \\
\hline \multicolumn{6}{|c|}{ Adverse event in family in last year } \\
\hline 0 & $53(37.9)$ & $74(52.9)$ & $13(9.3)$ & 140 & \multirow[t]{4}{*}{0.06} \\
\hline 1 & $27(34.6)$ & $43(55.1)$ & $8(10.3)$ & 78 & \\
\hline 2 or more & $9(28.1)$ & $14(43.8)$ & $9(28.1)$ & 32 & \\
\hline Total & $89(35.6)$ & $131(52.4)$ & $30(12)$ & 250 & \\
\hline
\end{tabular}

${ }^{*} P<0.05$ was considered significant. 
Table 2: Variables associated with satisfaction with the choice of profession, i.e., being a doctor, as compared to other professions, among the $\mathbf{2 5 0}$ doctors working in a tertiary hospital

\begin{tabular}{|c|c|c|c|c|}
\hline Variable & $\begin{array}{c}\text { Satisfied } \\
n(\%)\end{array}$ & $\begin{array}{c}\text { Dissatisfied } \\
n(\%)\end{array}$ & $\begin{array}{c}\text { Total } \\
n\end{array}$ & $P^{*}$ \\
\hline \multicolumn{5}{|l|}{ Gender } \\
\hline Male & $83(50)$ & $83(50)$ & 166 & \multirow[t]{2}{*}{0.02} \\
\hline Female & 29 (34.5) & 55 (65.5) & 84 & \\
\hline \multicolumn{5}{|l|}{ Marital status } \\
\hline Single & 87 (49.7) & $88(50.3)$ & 175 & \multirow[t]{2}{*}{0.02} \\
\hline Married & $24(33.3)$ & $48(66.7)$ & 72 & \\
\hline \multicolumn{5}{|l|}{ Work-hours/day } \\
\hline$\leq 8$ hours & 38 (43.2) & $50(56.8)$ & 88 & \multirow{2}{*}{0.71} \\
\hline$>8$ hours & $74(45.7)$ & $88(54.3)$ & 162 & \\
\hline \multicolumn{5}{|l|}{ Night-shifts/month } \\
\hline 0 & $25(45.5)$ & $30(54.5)$ & 55 & \multirow{3}{*}{0.04} \\
\hline$<8$ & 45 (37.5) & 75 (62.5) & 120 & \\
\hline$\geq 8$ & $42(56)$ & $3(44.0)$ & 75 & \\
\hline \multicolumn{5}{|c|}{ Adverse event in family in last year } \\
\hline 0 & $77(55.0)$ & $63(45.0)$ & 140 & \multirow[t]{3}{*}{0.001} \\
\hline 1 & $27(34.6)$ & $51(65.4)$ & 78 & \\
\hline$>1$ & $8(25.0)$ & $24(75.0)$ & 32 & \\
\hline \multicolumn{5}{|l|}{ Choice of profession } \\
\hline Own & $107(52.2)$ & $98(47.8)$ & 205 & \multirow[t]{3}{*}{$<0.001$} \\
\hline Family pressure & $5(11.1)$ & $40(88.9)$ & 45 & \\
\hline Total & $112(44.8)$ & $138(55.2)$ & 250 & \\
\hline
\end{tabular}

${ }^{*} P<0.05$ was considered significant

However, it was not significantly associated with gender (Chi-square $=0.74, P=0.83$ ), marital status (Chi-square $=0.69, P=0.44$ ), designation (Chi-square $=8.10, P=0.46$ ) or the number of work-hours per day (chi square $=0.02, P=0.90)$.

\section{Satisfaction with salary}

About half $(114 ; 45.6 \%)$ of the doctors considered their salary to be 'bad,' while $99(39.6 \%)$ considered it as 'average,' and only $37(14.8 \%)$ considered it to be 'good.' Dissatisfaction with salary was significantly higher in doctors who were interns (Chi-square $=21.69, P=0.001$ ) and those who had $\geq 8$ night shifts per month (Chi-square $=14.24$, $P=0.007$ ). However, it was not significantly associated with gender (Chi-square $=0.65$, $P=0.72$ ) and the number of work-hours per day (Chi-square $=5.48, P=0.06)$.

\section{Satisfaction with profession}

Satisfaction with their choice of profession, i.e., being a doctor, as compared to other professions was also asked about. More than half $(138 ; 55.2 \%)$ of the doctors were found to be dissatisfied. Dissatisfaction with profession was significantly more in the doctors who were married (Chi-square $=5.53, P=0.02$ ), females (Chi-square $=5.40, P=0.02$ ), those who joined this profession under family pressure (Chisquare $=25.17, P<0.001$ ), and those who had $\geq 8$ night shifts per month (Chi-square $=6.40$, $P=0.04)$ [Table 2].

\section{DISCUSSION}

In the present study, it was found that the doctors who had an average of more than 8 work-hours per day were more likely to be dissatisfied with the number of working hours per day. Similar results were found in the study by Appleton among general practitioners in Leeds $^{[6]}$; and by Brondt, in Denmark. ${ }^{[7]}$ The doctors who had more night shifts were found 
to be more dissatisfied with their job, which was also found by Sehlen among physicians in Germany. ${ }^{[8]}$

Majority $(88 \%)$ of the doctors perceived their work environment as good/average, which is similar to the results found by Madaan, who found that majority $(76.7 \%)$ of the residents in a tertiary hospital in Delhi perceived their

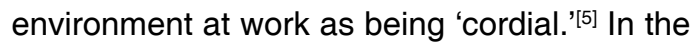
present study, salary was considered good by only $14.8 \%$ of the doctors, while Madaan found that about $27 \%$ of the doctors (faculty in addition to the residents) said that their salary was proportional to the workload. ${ }^{[5]}$ The sample population in the present study consisted of doctors with tenure posts only, whose salary was lower than the permanent faculty.

About half of the doctors were satisfied with their profession. Similar results have been found in a study by Frank among the physicians in the U.S. ${ }^{[9]}$ In our study, it was found that males were more satisfied with their profession, but Keeton in the U.S. ${ }^{[10]}$ and Cujec in Canada ${ }^{[11]}$ found that gender was not a strong independent predictor. This difference may be attributed to cultural differences in the context of these studies.

The present study has some limitations. Job satisfaction has various individual, departmental and institutional dimensions, out of which the latter was not studied. The sample did not cover doctors of all designations. The data was collected before the Sixth Pay Commission revised the salaries of doctors, so the figures on 'satisfaction with salary' may have changed after such revision of salaries.

\section{CONCLUSION}

A significant proportion of doctors were found to be dissatisfied with the average number of their working hours and salary. Many of them did not perceived their work environment as 'good'. Factors like the average number of work-hours per day and the number of night shifts per month were found to have a significant association with dissatisfaction. Further studies are needed to explore how best the work-hours of doctors could be adjusted to improve job satisfaction among them; and also to explore the influence of such high levels of dissatisfaction among doctors on their own health, on the optimal provision of patient care, and on the society as a whole.

\section{ACKNOWLEDGMENT}

We are thankful to all the doctors of our institute who participated and cooperated in this study.

\section{REFERENCES}

1. Haas JS, Cook EF, Puopolo AL, Burstin HR, Cleary PD, Brennan TA. Is the professional satisfaction of general internists associated with patient satisfaction? J Gen Intern Med 2000;15:122-8.

2. DiMatteo MR, Sherbourne CD, Hays RD, Ordway L, Kravitz RL, McGlynn EA, et al. Physicians' characteristics influence patients' adherence to medical treatment: Results from the Medical Outcomes Study. Health Psychol 1993;12: 93-102.

3. Khuwaja AK, Qureshi R, Andrades M, Fatmi Z, Khuwaja NK. Comparison of job satisfaction and stress among male and female doctors in teaching hospitals of Karachi. J Ayub Med Coll Abbottabad 2004;16:23-7. 
4. Janus K, Amelung VE, Gaitanides M, Schwartz FW. German physicians "on strike"--shedding light on the roots of physician dissatisfaction. Health Policy 2007;82:357-65.

5. Madaan N. Job satisfaction among doctors in a tertiary care teaching hospital. JK Sci 2008;10: 81-3.

6. Appleton K, House A, Dowell A. A survey of job satisfaction, sources of stress and psychological symptoms among general practitioners in Leeds. Bir J Gen Pract 1998;48:1049-63.

7. Brondt A, Vedsted P, Olesen F. General practitioners' job satisfaction. Ugeskr Laeger 2007;169:2521-5.

8. Sehlen S, Vordermark D, Schafer C, Herschbach $\mathrm{P}$, Bayerl A, Pigorsch S, et al. Job stress and job satisfaction of physicians, radiographers, nurses and physicists working in radiotherapy:
A multicenter analysis by the DEGRO Quality of Life Work Group. Radiat Oncol 2009;4:6.

9. Frank E, McMurray JE, Linzer M, Elon L. Career satisfaction of US women physicians: Results from the Women Physicians' Health Study. Arch Intern Med 1999;159:1417-26.

10. Keeton K, Fenner DE, Johnson TR, Hayward RA. Predictors of physician career satisfaction, work-life balance, and burnout. Obstet Gynecol 2007;109:949-55.

11. Cujec B, Oancia T, Bohm C, Johnson D. Career and parenting satisfaction among medical students, residents and physician teachers at a Canadian medical school. CMAJ 2000;162: 637-40.

Source of Support: Nil, Conflict of Interest: None declared.

\section{Author Help: Reference checking facility}

The manuscript system (w w w.journalonw eb.com) allows the authors to check and verify the accuracy and style of references. The tool checks the references with PubM ed as per a predefined style. Authors are encouraged to use this facility, before submitting articles to the journal.

- The style as well as bibliographic elements should be $100 \%$ accurate, to help get the references verified from the system. Even a single spelling error or addition of issue number/month of publication will lead to an error when verifying the reference.

- $\quad$ Example of a correct style Sheahan P, O'leary G, Lee G, Fitzgibbon J. Cystic cervical metastases: Incidence and diagnosis using fine needle aspiration biopsy. Otolaryngol Head Neck Surg 2002;127:294-8.

- $\quad$ Only the references from journals indexed in PubM ed will be checked.

- $\quad$ Enter each reference in new line, without a serial number.

- Add up to a maximum of 15 references at a time.

- If the reference is correct for its bibliographic elements and punctuations, it will be shown as CORRECT and a link to the correct article in PubM ed will be given.

- If any of the bibliographic elements are missing, incorrect or extra (such as issue number), it will be shown as INCORRECT and link to possible articles in PubM ed will be given. 